\title{
Evaluation of Incidental Thyroid Cancer in Patients with Thyroidectomy
}

\author{
V Taşova, B Kilicoglu, S Tuncal, E Uysal, MZ Sabuncuoglu, Y Tanrikulu, A Aydogan, AK Onalan, S Dinc, MA Akkus
}

\begin{abstract}
Objective: The present study aimed to emphasize the necessity and significance of thyroidectomy by determining the prevalence of incidental thyroid cancer in the cases that underwent surgical intervention for the treatment of benign thyroid disease.

Subjects and Method: Thyroidectomy was performed in 443 cases including those with benign multinodular goitre (BMNG) or toxic adenoma or toxic multinodular goitre. Diagnosis was made based on routine physical examination, laboratory analyses, imaging methods and postoperative histopathological findings of the cases.

Results: The mean age of the cases was $45.5(19-68)$ years and $72.5 \%(n=321)$ were female. The most common clinical diagnosis prior to the surgery was BMNG $(n=428,96.6 \%)$. While BMNG was determined to be the most common histopathological diagnosis after thyroidectomy at a rate of $81.7 \%$ $(n=362)$, the rate of thyroid cancer was found to be $14 \%(n=81)$. The prevalence of papillary cancer was $84 \%(n=56)$, whereas it was $4 \%(n=4), 1 \%(n=1)$ and $0.0 \%(n=0)$ for medullary, follicular and anaplastic cancers, respectively. Papillary cancer was also the most common type of thyroid cancer between genders. As compared to gender, there was no statistically significant difference in terms of distribution of age among general, benign and malignant types of thyroid cancer ( $\mathrm{p}>0.05)$.

Conclusion: It is appropriate to prefer thyroidectomy for the treatment of benign thyroid diseases due to the high prevalence of incidental thyroid cancer after thyroidectomy in such cases.
\end{abstract}

Keywords: Nodular goitre, thyroid cancer, thyroidectomy

\section{Evaluación Incidental del Cáncer de Tiroides en Pacientes con Tiroidectomía}

V Taşova, B Kilicoglu, S Tuncal, E Uysal, MZ Sabuncuoglu, Y Tanrikulu, A Aydogan, AK Onalan, S Dinc, MA Akkus

\section{RESUMEN}

Objetivo: El presente estudio tiene por objeto destacar la necesidad e importancia de la tiroidectomía mediante la determinación de la prevalencia del cáncer de tiroides incidental en los casos sometidos a intervención quirúrgica para el tratamiento de enfermedades tiroideas benignas.

Sujetos y método: Se practicó la tiroidectomía en 443 casos incluyendo aquellos con bocio multinodular benigno $(B M N G)$ o adenoma tóxico o bocio multinodular tóxico. El diagnóstico se realizó a partir de un examen físico de rutina, análisis de laboratorio, métodos de imaginología, y resultados histopatológicos postoperatorios de los casos.

Resultados: La edad promedio de los casos fue 45.5 años $(19-68)$ y $73 \%(n=321)$ eran mujeres. El diagnóstico clínico más común antes de la cirugía fue BMNG $(n=428,96,6 \%)$. Si bien se determinó que BMNG era el diagnóstico histopatológico más frecuente después de la tiroidectomía con una tasa de $81.7 \%(n=362)$, se halló que la tasa de cáncer de tiroides era $14 \%(n=81)$. La prevalencia de cáncer papilar fue de $84 \%(n=56)$, mientras que para el cáncer medular, folicular y anaplásico, fue de $4 \%(n=4), 1 \%(n=1)$ y $0.0 \%(n=0)$ respectivamente. El cáncer papilar también fue el tipo más común de cáncer de tiroides entre los géneros. En comparación con el género, no hubo ninguna diferencia estadísticamente significativa en cuanto a la distribución por edad entre los tipos generales, benignos y malignos de cáncer de tiroides ( $\mathrm{p}>0.05)$.

From: Department of General Surgery, Ankara Training and Research Hospital, Ankara, Turkey.
Correspondence: Dr B Kilicoglu, Ankara Eğitim ve Araştirma Hastanesi Genel Cerrahi, Altındağ, Ankara, Turkey 06370. E-mail: kilicoglubulent@yahoo.com 
Conclusión: Es apropiado preferir la tiroidectomía para el tratamiento de las enfermedades tiroideas benignas debido a la alta prevalencia de cáncer tiroideo incidental después de la tiroidectomía en tales casos.

Palabras claves: Bocio nodular, cáncer de tiroides, tiroidectomía

West Indian Med J 2013; 62 (9): 845

\section{INTRODUCTION}

Thyroid cancers are the most common endocrine system cancers and account for approximately $1 \%$ of clinical cancers. In general, they have good prognosis since they show slow progression; however, they have the highest mortality rate among overall cancers of endocrine organs. Multinodular goitre (MNG) is the most common endocrine disease that requires a surgical intervention. Today, total thyroidectomy (TT) is being widely used for the treatment of both malignant and benign thyroid diseases (1).

It is known that relapse rates after subtotal thyroidectomy (ST) reaches up to 50\% during long-term follow-up of MNG (2). Many retrospective studies with evidence level of four and many prospective studies with evidence level of two demonstrate the frequency of relapses with lesser excisions than TT $(1,3)$. Thyroid cancer has been incidentally found in those studies, thus ST is not recommended because of not providing adequate cancer treatment. In the last decade, TT has been used for the treatment of MNG owing to it relieving symptoms, eliminating the risk for relapses and providing adequate treatment for incidental thyroid cancers (3). Today, along with the widespread use of fine needle aspiration biopsy (FNAB) for diagnosis and detailed examination of biopsy materials by the pathologists, the rate of detection of microcancers, which are not clinically manifested, has been gradually increasing (4).

The present study aimed to evaluate the patients who underwent thyroidectomy for benign reasons and in whom incidental thyroid cancer was detected, to determine the prevalence of incidental thyroid cancer, to show that physical examination, ultrasound findings and family history are as important as FNAB, and to show the benefits of total thyroidectomy performed in such patients.

\section{SUBJECTS AND METHOD}

The present study was performed based on the records of patients who underwent thyroidectomy for any reason other than thyroid cancer between March 2007 and May 2011 in the General Surgery Clinic of the Ministry of Health, Ankara Training and Research Hospital. Age at surgery, gender, physical examination findings, ultrasound findings, family history for thyroid nodule, history of radiation to the head and neck region, presence of short-term changes in the nodule, results of FNAB if any, and the last pathology reports of the patients who had been diagnosed with thyroid cancer after surgery despite the absence of cancer diagnosis before the surgery, were recorded.
A total of 443 patients had undergone primary thyroid surgery between the above-mentioned dates. The mean age of the patients was 45.5 (19-68) years. Patients less than 20 years and those over 45 years were considered as the highrisk age groups. Three hundred and twenty-one $(72.5 \%)$ of the patients were female. Of the patients, 401 underwent total thyroidectomy $(90.5 \%), 34$ (7.6\%) underwent lobectomy together with isthmectomy, and eight $(1.8 \%)$ underwent subtotal thyroidectomy. Pathology reports of the surgical materials of $66(14.9 \%)$ patients among the 443 who underwent thyroidectomy revealed thyroid cancer. Preoperative biopsies of 15 patients revealed malignant disease and these patients were excluded from the study. Sixty-six patients, who did not have a preoperative malignancy diagnosis but were diagnosed with thyroid cancer based on the pathology report after the surgery, were included in the study.

Overall main pathology results, which have been identified as papillary, follicular, hurtle-cell, medullary, and anaplastic, as well as the microcarcinomas smaller than $1 \mathrm{~cm}$, lymphoma, and the metastatic cancers of the thyroid were considered malignant. All other lesions, including goitre, adenoma, hurtle-cell adenoma, hyperplasia and thyroiditis were considered benign.

Based on the results of FNAB, thyroid carcinoma, malignant cells, either of lymphoma or metastatic disease, as well as suspicious results were considered malignant and excluded from the study. Statistical analyses of data were done using SPSS 15.0 (Chicago, USA) package programme. Demographic characteristics and the ratio of the diseases were represented as percentage, mean, standard deviation, median, minimum and maximum. Comparisons were done using Student's $t$-test. A $p$-value smaller than 0.05 was considered significant.

\section{RESULTS}

Pathology results revealed malignancy in 66 patients who underwent surgical procedure for perceived benign reasons and thyroid cancer was discovered incidentally. The mean age of the patients was 45.5 (19-68) years. Patients younger than 20 years and patients older than 45 years were considered to be in the high-risk age group. Of the patients with malignancy, $57(86 \%)$ were female.

The size of thyroid resection was decided according to ultrasound findings, physical examination findings, risk status, socio-economic status, and complications of resurgery in the event of probable malignancy. Accordingly, patients with preoperative malignancy, unresponsiveness to 
thyroid suppression therapy, signs of local pressure eg hoarseness and dysphagia, metastatic disease, or the patients who had risk factors due to geographical reasons underwent total thyroidectomy. Patients without any of the above-mentioned risk factors and the patients without preoperative malignancy signs underwent lobectomy together with isthmectomy. The width of the resection was decided after the thyroid gland and surrounding soft tissues were examined in terms of macroscopic appearance and extracapsular involvement etc in the patients who were in neither of these two groups.

All patients underwent total thyroidectomy. In the present study, 52 (78.8\%) of the patients with incidental thyroid cancer were between the ages of 20 and 60 years, $12(18 \%)$ were over the age of 60 years, and two $(3 \%)$ were under the age of 20 years. Complete total thyroidectomy was performed in two patients who underwent lobectomy because the pathology report indicated malignancy. Preoperative FNAB was performed in 30 of 81 thyroid carcinoma cases. The results of FNAB revealed atypical cytology in eight $(26.7 \%)$, benign disease in one $(3.3 \%)$ and non-diagnostic cytology in six (20\%) of these patients. Fifteen $(50 \%)$ of the patients were diagnosed with malignancy (Table 1).

Table 1: Preoperative fine needle aspiration biopsy (FNAB) and postoperative pathology results

\begin{tabular}{lllc}
\hline Results of FNAB & $\mathbf{n}=\mathbf{3 0}$ & $\begin{array}{l}\text { Postoperative } \\
\text { pathology }\end{array}$ & $\mathbf{n = 6 6}$ \\
\hline Non-diagnostic cytology & $6(20 \%)$ & Papillary cancer & $56(84.8 \%)$ \\
Benign & $1(3.3 \%)$ & Follicular neoplasia & $4(6 \%)$ \\
Atypical cytology & $8(26.7 \%)$ & Undefined potential & $6(9 \%)$ \\
Malignant & $15(50 \%)$ & for malignancy & \\
\hline
\end{tabular}

Pathology results revealed malignancy in 81 patients out of 443 . Of the 66 patients without preoperative diagnosis of malignancy, the majority - $56(84.8 \%)$ had papillary carcinoma, four (6\%) had follicular neoplasia, and six $(9 \%)$ had unknown potential for malignancy (Table 1). Considering the size of nodules, it was between 15 and $40 \mathrm{~mm}$ in 33 $(50 \%)$, under $15 \mathrm{~mm}$ in $29(43.9 \%)$ and over $40 \mathrm{~mm}$ in 4 (6\%) patients (Table 2).

Table 2: Potential for malignancy considering the nodule size

\begin{tabular}{lclr}
\hline Nodule size & $\mathbf{n}$ & Nodule ultrasound & n \\
\hline$<15 \mathrm{~mm}$ & $29(44 \%)$ & Solid & $47(71.2 \%)$ \\
$15-40 \mathrm{~mm}$ & $33(50 \%)$ & Calcified & $11(16.7 \%)$ \\
$>40 \mathrm{~mm}$ & $4(6 \%)$ & Cystic & $8(12.1 \%)$ \\
\hline
\end{tabular}

Seventeen patients underwent preoperative scintigraphy. Nine $(52.9 \%)$ of these patients had hypoactive, five (29\%) had hyperplasic, two (11.7\%) had cold nodules and one (5.8\%) had thyroiditis. Six (9\%) of 66 patients exhibited postoperative thyroglobulin elevation, which regressed to normal level within the first postoperative year. Eight
(12.1\%) patients had hyperthyroidism and were euthyroid preoperatively, with antithyroid medications. One (1.5\%) patient had hypothyroidism.

\section{DISCUSSION}

Thyroid nodule, which is likely to comprise various pathologies, is the most common thyroid disease. The worldwide prevalence of palpable nodule is approximately 4-7\% (5) and $0.8 \%$ nodule is being detected each year. The prevalence can reach up to $30-50 \%$ on ultrasound or in autopsy series.

Thyroid nodules and goitre are quite common in Turkey. Some studies from Turkey reported the prevalence of thyroid nodule to be $40 \%$ between the ages 25 and 60 years.

The term solitary nodule or solitary nodular goitre is used in cases where there is a single nodule, either normalsized or enlarged, in the thyroid; the term multinodular goitre is used when there is more than one nodule. Although the majority of these nodules are benign, suspicion of potential malignancy in these nodules causes anxiety in both the patient and the physician. The rate of malignancy is $4.7 \%$ in solitary nodules, $4.1 \%$ in dominant nodule, and $1 \%$ in multinodules. These rates suggest that multinodular goitre with dominant nodule should be considered as solitary nodule (6).

There are two extreme points, conservative approach or extended surgical resection, in the treatment of risky nodules. However, surgery is mandatory in the cases having a risk for malignancy (7). Risk factors for malignancy can be assessed by a detailed anamnesis and physical examination. Patients under the age of 20 years or over the age of 60 years, who have thyroid nodules, are in the high risk group for thyroid cancer. In the present study, however, 78.8\% $(n=52)$ of the patients with incidental thyroid cancer were between the ages 20 and 60 years.

The risk for the nodule to be malignant is increased in the presence of family history for papillary, hurtle-cell or medullary cancer (8). History of radiation to the head and neck region is the leading cause that increases the risk for differentiated thyroid cancer. A study on this subject demonstrated that $37 \%$ of the patients who were exposed to radiation in childhood and followed for 30 to 40 years, developed thyroid nodule whereas $10 \%$ developed thyroid cancer (9). Turkey has been affected by the Chernobyl nuclear accident in 1986. There are opinions suggesting that this disaster has increased the cancer incidence in Turkey; however, there is no accepted study on this subject yet.

Progressive or rapid enlargement of a solitary or dominant nodule, the majority of which is asymptomatic or incidentally detected during physical examination, evokes the probability of malignancy. Intranodular haemorrhage is thought if a nodule displays painful and rapid enlargement within days, even hours.

Solid and fixed nodules are usually malignant, whereas benign nodules are soft. Nevertheless, some papillary and follicular cancers may become soft due to cystic degen- 
eration or the nodule may be mixed as is the case in papillary cancer. The probability of malignancy is higher for solitary nodules larger than $3 \mathrm{~cm}$ in diameter. In the present study, mean nodule size was $17 \mathrm{~mm}$ in the malignant cases and smaller than $40 \mathrm{~mm}$ in $94 \%$ of incidental thyroid cancers. Here, physical examination, ultrasound and FNAB findings have gained importance rather than the size of nodule.

On ultrasound, a nodule being hypoechogenic and irregular, having microcalcification, absence of surrounding halo, invading the surrounding tissues, presence of accompanying cervical lymphadenopathy, and being solid are the findings in favour of malignancy. Hyperechogenity, regular contour, colloidal content, absence of accompanying cervical lymphadenopathy and low blood flow-rate in the nodule are the findings in favour of a benign condition.

In the present study, $72 \%$ of nodules were solid and fixed and $16 \%$ were calcified, suggesting that a detailed physical examination, ultrasound and precise FNAB are of great importance.

Scintigraphy is a method frequently used to evaluate thyroid nodules. Scintigraphy is unable to distinguish benign lesions from malignant lesions (10), but identifies the functional status of the nodule. Nodules are divided into three groups according to radioisotope uptake: cold, warm or hot. The risk for malignancy was approximately $16 \%$ for cold nodules, $9 \%$ for warm nodules and $4 \%$ for hot nodules (9).

In the present study, 17 of 66 patients with incidental thyroid cancer had undergone preoperative scintigraphy; of these, nine $(52.9 \%)$ had hypoactive, five $(29.4 \%)$ had hyperplasic and two (11.8\%) had cold nodules, whereas one had thyroiditis.

The primary goal of FNAB is to prevent unnecessary surgical interventions, which are performed because of the probability of nodules being malignant. Fine needle aspiration biopsy is the most suitable method for malignancy detection in almost all patients with thyroid nodule. However, FNAB is not performed for the nodules with autonomous function, since almost all of them are benign. The smallest appropriate nodule size for the test is $1 \mathrm{~cm}$. Patients with differentiated thyroid carcinoma smaller than $1 \mathrm{~cm}$ have life expectancy equal to that of the normal population. In our region, patients' low socio-economic status and noncompliance with follow-up visits make monitoring of these nodules difficult and usually surgery is required at the time of diagnosis.

Although FNAB is quite a reliable and low-cost method, accuracy varies between $50 \%$ and $97 \%$ depending on the experience of the pathologists $(10,11)$.

In the present study, 30 of 81 cases with thyroid cancer had undergone FNAB. Pathological reports of these patients revealed malignancy in $15(50 \%)$, atypical cytology in eight $(26.7 \%)$, non-diagnostic cytology in six $(20 \%)$, and benign disease in one (3.3\%). Accuracy of FNAB remaining at 50\% despite the prevalence of thyroid cancer being $18 \%$ has directed us to a more careful history taking and physical examination in terms of malignancy, and preoperative surgical findings and macroscopic appearance of the tissue have gained importance.

Erbil et al reported the prevalence of thyroid cancer after thyroidectomy to be $11 \%$ in the cases with benign multinodular goitre. In the present series, incidental thyroid cancer was detected in $66(14.9 \%)$ of 443 cases and the rate was considered similar (12).

Based on these data, results of detailed anamnesis, physical examination and FNAB should be considered together as a whole, instead of individual evaluation of demographic characteristics such as age and gender, thyroid function tests and imaging methods. The diagnosis and treatment of thyroid cancer should be approached in this way.

In the present study, the prevalence of papillary thyroid cancer was $84.8 \%(n=56)$ in the 66 patients with malignancy and this prevalence already being $80 \%$ in the literature directed us to perform total thyroidectomy. Papillary thyroid carcinoma is multifocal and thyroid tissue is required to be completely removed for radioactive iodine therapy. Moreover, dissection of central lymphatic group (prelaryngeal, pretracheal, prethyroid, paratracheal) should be involved in the surgical procedure if needed. We concluded that total thyroidectomy should be chosen for the treatment of thyroid nodules, even if they are benign, and central lymph node dissection should be included in the cases with preoperative suspicious cancer.

\section{REFERENCES}

1. Agarwal G, Aggarwal V. Is total thyroidectomy the surgical procedure of choice for benign multinodular goitre? An evidence-based review. World J Surg 2008; 32: 1313-24.

2. Rios A, Rodriguez JM, Galindo PJ, Montoya MJ, Canteras M, Parrilla P. Surgical treatment of multinodular goiter in young patients. Endocrine 2005; 27: 245-52.

3. Giles Y, Boztepe H, Terzioglu T, Tezelman S. The advantage of total thyroidectomy to avoid reoperation for incidental thyroid cancer in multinodular goitre. Arch Surg 2004; 139: 179-82.

4. Delbridge L. Total thyroidectomy: the evolution of surgical technique. Aust N Z J Surg 2003; 73: 761-8.

5. O’Donnell AL, Spaulding SW. Hyperthyroidism: systemic effects and differential diagnosis. In: Falk SA, ed. Thyroid disease: endocrinology, surgery, nuclear medicine, and radiotherapy. $2^{\text {nd }}$ ed. Philadelphia: Lippincott-Raven; 1997: 241-252.

6. Cusick EL, Krukowski ZH, MacIntosh CA, Matheson NA. Risk of neoplasia and malignancy in "dominant" thyroid swellings. BMJ 1991; 303: $20-4$.

7. De Groot LJ. Most solitary thyroid nodules should be removed. In: Ingelfinger FJ, Ebert RV, Finland M, Relman AS, eds. Controversy in internal medicine. Volume 2. Philadelphia: WB Saunders 1974: 421427

8. Giuffrida D, Gharib H. Controversies in the management of cold, hot and occult thyroid nodule. Am J Med 1995; 99: 642-50.

9. Efremidou EI, Papageorgiou MS, Liratzopoulos N, Manolas KJ. The efficacy and safety of total thyroidectomy in the management of benign thyroid disease: a review of 932 cases. Can J Surg 2009; 52: 39-44.

10. Madden PR, Wheeler MH. Approach to thyroid nodules. In: Clark OH, Duh Q-Y, eds. Textbook of endocrine surgery. Philadelphia: WB Saunders; 1997: 69-74.

11. Vaiman M, Nagibin A, Hagag P, Buyankin A, Olevson J, Shlamkovich N. Subtotal and near total versus total thyroidectomy for the management of multinodular goiter. World J Surg 2008; 32: 1546-51. 
12. Erbil Y, Barbaros U, Salmaslioğlu A, Yanik BT, Bozbora A, Ozarmağan S. The advantage of near-total thyroidectomy to avoid postoperative hypoparathyroidism in benign multinodular goiter. Langenbecks Arch Surg 2006; 391: 567-73. Epub 2006 Sep 21. 